\title{
O FANTÁSTICO MACHADIANO E O CONTEXTO DO RIO DE JANEIRO DO SÉCULO XIX EM “A CHINELA TURCA", “O ESPELHO" E "ENTRE SANTOS"
}

\section{Renata Philippov}

Resumo: Este artigo objetiva analisar os contos machadianos "A Chinela Turca", "O Espelho: esboço de uma teoria da alma humana" e "Entre Santos" à luz do modo fantástico, buscando compreender como o contexto sócio-histórico do autor, o Rio de Janeiro do século XIX, ajuda a construir a verossimilhança e, ao mesmo tempo, subvertê-la. Para tal, tomaremos por base os estudos de Iveson (2008) e Roas (2014), em relação aos conceitos de tropo do fantástico, de desmembramento da realidade e de hiper-realismo.

Palavras-chave: Conto machadiano. Fantástico. Contexto sócio-histórico.

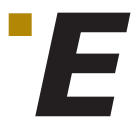

m seu artigo sobre o tropo fantástico e o desmembramento da realidade, Iveson (2008) cita Paulhan (2006) em relação ao "tropo do inesperado" - o que, segundo o primeiro, incorpora, e é exemplificado pelo tropo fantástico - como espécie de metonímia, de algo inesperado mas pertencente, enquanto pedaço, a algo já familiar:

Para que uma imagem nos apareça de forma inesperada, os dois objetos trazidos juntos por ela ainda devem ser familiares. Podemos ser tocados pela visão de um cavalo alado, porque já possuímos a ideia familiar, de quase senso comum, de um cavalo e de asas. Se o próprio cavalo nos fosse assombroso de qualquer maneira, não nos surpreenderíamos mais por vê-lo voar do que correr (PAULHAN, 2006 apud IVESON, 2008, p. 5, tradução nossa).

No entender de Iveson (2008, p. 5, tradução nossa), o tropo fantástico não está atrelado a algo totalmente inusitado ou desconhecido (o que, talvez, nos pudesse fazer pensar no maravilhoso, no reino de fadas), pois "não é nem pode ser pura invenção no sentido estrito de radicalmente outro, mas sim espécie de quimera, aquele monstro mítico com a cabeça de leão, cauda de cobra e corpo de bode especificamente mencionado por Sócrates em diálogo sobre retórica”. 
Assim como na metáfora do cavalo alado citada por Paulhan, aqui também teríamos algo semelhante na figura da quimera: reconhecemos o cavalo, as asas, o leão, a cobra e o bode, todos elementos familiares, mas sua junção causa estranhamento ou o tropo do inesperado.

Mais adiante em seu artigo, Iveson cita o conceito de autolegitimização de Derrida (1992 apud IVESON, 2008, p. 9, tradução nossa) em relação ao apagamento de interpretações desviantes da norma, o que cria "a ilusão de ordem ou do apropriado como natural que o tropo do fantástico tanto explora quanto assombra". Ou seja, o fantástico, segundo Iveson (2008), traria a construção da ilusão da ordem, de algo natural, que, ao mesmo tempo em que nos é familiar, também nos assombra. Isso nos remete, no entender de Iveson e no nosso também, ao conceito freudiano de Das Unheimliche, ou de estranho, inquietante ou não familiar, tal como discutido em ensaio homônimo.

Assim, o excesso de uso de tropos recontextualizados, ou legitimados pela ilusão de ordem, ou seja, de tropos vistos como estranhos quando em conjunção, mas tidos como aceitáveis e apropriados, quando isolados, ao serem inseridos dentro de uma narrativa dita "realista" e congruente com o horizonte de expectativa do leitor e nela causando ruptura em relação ao real ou à representação mimética da realidade, cria estranhamento ou desmembramento da realidade. Além disso, chamam a atenção para a construção discursiva do texto e para a ilusão de apropriado ou de não familiar dentro do familiar, tal como discutido por Freud (1955 apud IVESON, 2008, p. 10, tradução nossa), que ocorre "quando a distinção entre imaginação e realidade é apagada, como quando algo que havíamos até então considerado imaginário aparece diante de nós como real".

Ou ainda, como diz Jackson (1981 apud IVESON, 2008, p. 13, tradução nossa),

[...] a literatura fantástica aponta para ou sugere a base sobre a qual se assenta a ordem cultural, pois se abre, por um breve momento, para a desordem, a ilegalidade, aquilo que está fora da lei e dos sistemas dominantes de valor. $O$ fantástico traça o não dito e o não visto da cultura: aquilo que pode ser silenciado, tornado invisível, acobertado e feito "ausente".

Em A ameaça do fantástico, Roas (2014) segue caminho paralelo e, por vezes, oposto ao de Iveson. Partindo de uma revisão de diferentes conceptualizações acerca do fantástico, tal como discutido por Caillois (1985), Bessière (1973), Todorov (2008), Furtado (1980) e Ceserani (2006), dentre outros, Roas (2014, p. 53) define o fantástico como mais realista, ou até mesmo hiper-realista, remetendo-se a Villanueva (1992, p. 172) do que a literatura propriamente dita realista:

[...] além de reproduzir as técnicas dos textos realistas, ele obriga o leitor a confrontar continuamente sua experiência da realidade com a dos personagens: sabemos que um texto é fantástico por sua relação (conflituosa) com a realidade empírica.

Segundo Roas (2014, p. 54), em vez de suspender a realidade objetiva, como discute Malrieu (1992), por exemplo, o fantástico apropria-se do senso de realidade empírica e dela se nutre para então rompê-la:

A narrativa fantástica está ambientada, então, em uma realidade cotidiana que ela constrói com técnicas realistas e ao mesmo tempo destrói, inserindo nela outra realidade, incompreensível para a primeira. Essas técnicas coincidem cla- 
ramente com as fórmulas utilizadas em todo texto realista para dar verossimilhança à história narrada, para afirmar a referencialidade do texto: recorrer a um narrador extradiegético-homodiegético, ambientar a história em lugares reais, descrever minuciosamente objetos, personagens e espaços, inserir alusões à realidade pragmática etc. Como vemos, ofantástico é um modo narrativo que provém do código realista, mas que ao mesmo tempo supõe uma transformação, uma transgressão desse código: os elementos que povoam o conto fantástico participam da verossimilhança própria da narração realista e unicamente a irrupção, como eixo central da história, do acontecimento inexplicável é que marca a diferenciação essencial entre o realista e o fantástico.

Nesse sentido, depende de uma inserção total no contexto sociocultural em que é produzida para criar senso de realidade e, ao mesmo tempo, de estranhamento, o que nos remete, mais uma vez, a Paulhan, Freud e Jackson, ou de desmembramento, como argumenta Iveson. Ainda segundo Roas (2014, p. 55), "o fenômeno fantástico, impossivel de explicar pela razão, supera os limites da linguagem: é por definição indescritivel porque é impensável". Assim, continua o crítico, o fantástico é profundamente subversivo tanto em termos temáticos quanto estilísticos, posto que calcado em discurso vago e impreciso por parte do narrador, discurso esse que passa a ser tomado por conotação (pleno de metáforas, neologismos, indefinições e modalizações discursivas). Assim, a precisão linguística do realismo é simultaneamente entremeada de imprecisão e indefinição, no entender de Roas. A nosso ver, parece ser o caso de, pelo menos, alguns dos contos ditos fantásticos de Machado de Assis, objeto deste artigo. Passemos, então, a brevemente ver como essa subversão, essa concomitância de hiper-realismo e indefinição aparecem na construção de alguns contos machadianos comumente associados ao modo fantástico, bem como o papel desempenhado pelo contexto, referido e recontextualizado nas narrativas em questão.

\section{“A Chinela Turca"1}

"A Chinela Turca", conto publicado originalmente em 1875 no jornal Época, sob pseudônimo de Manassés, e pertencente ao volume Papéis avulsos (publicado originalmente em 1882), conta a história do jovem bacharel Duarte, que, em 1850, está se vestindo e preparando ansiosamente para um baile onde encontrará sua amada. É inesperadamente interrompido em seus preparativos pela visita de uma personagem que havia decidido tornar-se um grande dramaturgo. Sem aviso prévio, tal visitante, o Major Lopo Alves, senta-se para ler um drama infindável e sem sentido, para desespero de Duarte, que vê o tempo passar e suas chances de um encontro romântico se esvaírem. De repente, o dramaturgo sai correndo sem nada dizer, mas Duarte percebe que é tarde demais para ir ao baile. A campainha toca novamente e um policial surge anunciando sua prisão pelo roubo de uma valiosa chinela turca: diz-nos o narrador que tal chinela pertenceria a uma dama recém-chegada de viagem ao Egito, comprada de um judeu, e ornada com ricos diamantes. Seu clamor de inocência parece inútil e Duarte é levado preso. No caminho para o distrito policial, entretanto, a carrua-

\footnotetext{
As citações dos três contos aqui analisados pertencem à seguinte edição: Assis (2015). Doravante, citaremos apenas as páginas de onde foram tiradas.
} 
gem para e ele é levado vendado a uma mansão enorme e caríssima, ricamente decorada com mobília arabesca. Segundo o narrador, o espaço lembra um labirinto com uma série de salas e portas que ele atravessa, uma após outra. De repente, alguém lhe diz para retirar a venda dos olhos e Duarte se vê só no recinto. Logo em seguida, ainda tentando conjecturar o que estava acontecendo, vê um padre passar, cumprimentá-lo e o abençoar, enquanto sente a opressão de um pêndulo a bater constantemente no recinto. Novamente surge a figura que o havia levado preso até ali, diz que não é policial e o leva a uma grande sala, onde encontra o dono da mansão, que lhe confessa que o roubo fora mero pretexto seu para fazer Duarte ser levado ao local. Logo em seguida, anuncia que Duarte deverá se casar com sua filha. Duarte protesta contra tal situação e se lembra de sua amada. No entanto, é interrompido pela chegada da filha do dono do imóvel, sua noiva. A linda figura surpreende-o pela beleza incomum (o narrador a descreve como uma "sílfide", uma figura sagrada e bastante semelhante fisicamente com Cecília, a namorada de Duarte), mas ele logo é avisado de que deverá se casar, assinar um testamento e ser envenenado até a morte. O pai da noiva fala de seu interesse pela fortuna de Duarte, cento e cinquenta contos, a serem herdados pela filha; quando aquele tenta se recusar a casar, é ameaçado por um revólver, e o pai da noiva anuncia que deverá, então, escolher a melhor forma de morrer. O padre reaparece, diz que, na verdade, é um militar e não um padre, e cochicha em seus ouvidos, aconselhando-o a fugir pela janela. Duarte assim o faz e corre desesperadamente pelos jardins da rica mansão até entrar em uma casa no meio do jardim, onde, com alivio, reencontra o dramaturgo calmamente sentado lendo sua obra. A história termina com a sensação de Duarte de que fora salvo pelo drama infindável que fora obrigado a ouvir, ruim em termos de conteúdo, mas bastante eficaz em seus efeitos no espectador. Diz-nos o narrador, reproduzindo em discurso direto a voz de Duarte, em cujos termos podemos notar a ironia machadiana ${ }^{2}$ :

- Ninfa, doce amiga, fantasia inquieta e fértil, tu me salvaste de uma ruim peça com um sonho original, substituíste-me o tédio por um pesadelo: foi um bom negócio. Um bom negócio e uma grave lição: provaste-me ainda uma vez que o melhor drama está no espectador e não no palco (p. 274).

Vale salientar que o narrador, logo no início do conto, se dirige a alguém como se com ele dialogasse (um interlocutor não referenciado na narrativa, talvez nós, leitores) na segunda pessoa do plural - "Vêde o bacharel Duarte" (p. 268), enquanto parece contar acontecimentos bastante verossímeis e criveis. Isso é dado por uma cronologia bastante marcada dos fatos e por alusões espaço-temporais precisas (a menção ao ano de 1850, a bairros bastante específicos do Rio de Janeiro, como Catumbi e Rio Comprido, aos renomados jornais Correio Mercantil e Jornal do Comércio). Além disso, o leitor é exposto a uma série de acontecimentos e elementos compatíveis com o Rio de Janeiro do Segundo Império, como o baile, a carruagem policial, a concepção de amor romântico entre Duarte e Cecília, além do detalhamento minucioso dos dois locais onde se passa a narrativa - a casa de Duarte e a imponente mansão de onde escapa -, e das personagens, figuras consideradas acima de qualquer suspeita, como um ba-

2 Machado de Assis dedicou-se longamente à crítica teatral, tanto em crônicas publicadas em jornais quanto de forma esparsa, por meio de alguns de seus contos, como podemos ver neste aqui. 
charel, filho de militar, ou um major, além da presença inusitada do padre/militar (figuras de autoridade), o que confere à narrativa verossimilhança e suscita no leitor maior credulidade (como duvidar dos fatos relatados pelo narrador, que teriam envolvido tais figuras acima de qualquer suspeita, se, além do mais, há vários detalhes bastante verídicos que servem para atestar que os fatos de fato ocorreram?). Ou seja, estamos diante do que Roas (2014) chama de hiper-realismo, ao mesmo tempo em que o leitor fica com a primeira impressão de algo solto na história, de um salto temporal, de uma narrativa dentro da outra, em planos encaixados. Afinal, o que aconteceu naquela noite do ano de 1850 ?

Uma leitura possivel seria a de se considerar que tudo não passou de um sonho de Duarte durante a leitura do drama, como suas palavras, citadas acima, parecem indicar. Nesse pesadelo incomum e labirintico sofrido por Duarte, haveria o aflorar de seu inconsciente latente, no sentido freudiano, em que o familiar e o insólito ou inesperado se mesclam (cf. PAULHAN, 2006; IVESON, 2008): o medo de perder a chance de dançar com Cecília teria sido transmutado na ameaça de um casamento forçado, seguido de morte, em que a figura militar do major teria sido mesclada com a do padre (quando este diz a Duarte que é militar, não padre, embora esteja vestido como esse), em que a sensação inicial de Duarte, preso em casa com a visita indesejada do major, teria sido reconfigurada com sua prisão absurda e infundada, em que o constante e irritado olhar o relógio por parte de Duarte, enquanto ouvia a leitura enfadonha do drama, no início da narrativa, teria sido transformada na presença opressora do pêndulo na mansão para onde foi levado. Embora interpretações factiveis da narrativa possam remeter a uma situação onírica, como dito acima, somente se fala em sonho no último parágrafo do conto e com ele se encerra a narrativa, sem mais explicações nem intercessões por parte do narrador. Em quase sua totalidade, o conto nos traz uma série de eventos minuciosamente detalhados e eventos interligados uns aos outros como em labirinto ou redemoinho de tempo, espaço e atmosfera nos quais as personagens e o leitor são presos, em intromissão insólita/onírica dentro da realidade objetiva e realisticamente descrita, do tropo do inesperado dentro do familiar, tal a metáfora do cavalo alado ou da quimera, com decorrente subversão de verossimilhança externa (cf. JACKSON, 1981). Afinal, o leitor reconhece os detalhes do Rio de Janeiro de seu tempo e as marcas contextuais deixadas pelo narrador e acredita no que lhe é relatado, mas a forma insólita com que os acontecimentos se encadeiam o surpreende.

É importante mencionar que, se em "A Chinela Turca" há um leve tom de comédia, pelo menos no começo, com a visita do dramaturgo, tal tom não é o de riso aberto e atmosfera leve, mas sim de sarcasmo, amargura e desespero. Sorri-se amargamente mais do que se ri alegremente quanto se leem os acontecimentos da narrativa, permeados de medo e incertezas por parte da personagem principal, Duarte. Ao final, o tom muda novamente, e se vê a ironia machadiana brevemente articulada à narrativa.

\section{"O Espelho: Esboço DE UMA TEORIA dA ALMA huMANA"}

"O Espelho", originalmente publicado em A Gazeta de Noticias, em 1882, e também pertencente à coletânea Papéis avulsos (publicada no mesmo ano), traz em seu subtítulo "esboço de uma teoria da alma humana" o anúncio da temáti- 
ca do conto: o universo da alma humana, ou seja, da mente. Passemos ao resumo da narrativa. $\mathrm{O}$ conto começa com um diálogo entre amigos que se reúnem certa noite para contar histórias transcendentais, ou seja, espécie de prólogo, recurso retórico bastante comum na literatura fantástica do século XIX e que serve de atestado da veracidade dos fatos narrados. Um deles relata a história de um jovem bastante humilde que se torna alferes da Guarda Nacional, baixa patente, o que, paradoxalmente, alça-o a um patamar social e financeiro mais elevado. Seus parentes, amigos e conhecidos passam gradativamente a bajulá-lo e somente chamá-lo por sua patente, Alferes. A personagem, então, torna-se cada vez mais orgulhosa de si mesma, de sua nova condição social, a ponto de esquecer seu verdadeiro nome e identidade. Um dia viaja a uma pequena localidade para visitar uma tia recém-viúva que mora em um pequeno sítio com um cunhado, alguns escravos e animais. Com o passar dos dias, os habitantes de tal lugarejo e a vizinhança no entorno também o tratam como uma autoridade e utilizam apenas sua patente para se endereçarem a ele. Quando, entretanto, chega a notícia da morte de um conhecido, a tia e o cunhado partem por alguns dias para os funerais, deixando a personagem sozinha para tomar conta da propriedade, dos escravos e dos animais. Começa, então, a perceber que os escravos o tratam com maior respeito e é convidado a participar de uma grande festa organizada por eles. No dia seguinte, após a celebração regada a vinho, danças e cantos, percebe que os escravos fugiram levando grande parte dos animais. Sem saber o que fazer, decide ficar esperando pela volta dos parentes, sozinho. Começa, então, a sentir solidão e desamparo com o passar do tempo. Tais sentimentos tornam-se desespero e angústia, a ponto de não mais cuidar de sua aparência e em não mais se olhar em um espelho que havia recebido de presente quando de sua chegada ao local. No entanto, um dia decide se vestir como antes e busca seu uniforme, simbolo de sua patente e valor. Automaticamente recupera a sensação de conforto e bem-estar.

A história termina com a retomada da ideia presente na introdução da narrativa: a de que há duas almas em cada ser humano, uma interna e outra externa. A primeira é a comumente tida como a dimensão religiosa do homem, alma que alcança os céus ou desce aos infernos com o fim da vida. A segunda é constituída pelo reconhecimento social, pela imagem que os outros fazem do homem, projetada especularmente pelos outros e absorvida pelo eu. O espelho simboliza a conexão entre ambas as almas, consideradas duplas uma da outra. A teoria anunciada no subtítulo concebido por Machado parece apontar para o fato de a alma interna não conseguir manter o ser humano em sua integridade: sem a alma externa, ou o reconhecimento social, o homem não consegue sobreviver. A alma interna, portanto, busca a externa como complemento, sem a qual o homem é fadado ao desespero, à angústia, à destruição, ou seja, nesse conto machadiano o eu não quer destruir o outro, parte inerente de si, mas sim o busca para se manter uno, vivo e íntegro. Ou seja, em "O Espelho", o outro é temporariamente destruído ou deixado de lado pela ausência social e pelo estado de depressão do eu. Assim que esse último recobre sua sanidade mental e autoconfiança, fenômeno metaforicamente representado pela ação de se usar um uniforme e de se olhar no espelho (seja um espelho concreto, seja um espelho metafórico representado pela sociedade sobre si), ambas as almas se reconciliam, o universo da mente entra em reequilíbrio e o homem é salvo da destruição psíquica. 
Embora a maior parte da narrativa seja dedicada ao fenômeno parcialmente inexplicável, o da duplicação do eu, a exemplo de "A Chinela Turca", está novamente inserida no contexto sociocultural da época em que foi escrito: a sociedade escravocrata do Segundo Império, o grande relevo dado a patentes militares, vistas como única forma de ascensão social para uma grande parcela da população mais desprivilegiada do Brasil de então, o desejo de liberdade dos escravos, vistos como ardilosos e, portanto, não confiáveis, por seus donos, a sociedade de aparências etc. Além disso, a narrativa traz riqueza de detalhes, e de nomes de personagens, a exemplo do que acontece em "A Chinela Turca", o que, mais uma vez, serve para asseverar os eventos narrados e torná-los criveis. Por outro lado, além de no prólogo, no qual os participantes da reunião noturna se agrupam para compartilhar relatos transcendentais, como nos diz o narrador, nesse conto não temos menção a sonhos ou pesadelos: a perda da alma exterior e sua retomada, ao final do conto, acontecem sem mais explicações, a não ser, talvez, o diálogo intertextual com o discurso filosófico, anunciado no subtítulo, como se este fosse, na verdade, uma ilustração esboçada sobre a teoria da alma humana, e, portanto, algo bastante crivel: afinal, como duvidar da filosofia? Essa parece ser a indagação final, fruto novamente da ironia machadiana. Nesse sentido, a concepção de fantástico, tal como discutida por Iveson (2008) e Roas (2014), mais uma vez parece corroborar o projeto narrativo machadiano.

\section{“ENTRe Santos”}

Outro conto machadiano que podemos mencionar aqui é "Entre Santos", originalmente publicado em 1896 no jornal Gazeta de Noticias e, posteriormente, nesse mesmo ano, na coletânea Várias Histórias. Nele, o narrador, padre velho, inicia falando que, quando jovem capelão de uma igreja, a S. Francisco de Paula, havia vivenciado a história narrada. Com esse início, a credulidade do leitor já é suscitada e o pacto narrativo já está posto, pois se trata do relato de um padre velho e, portanto, alguém acima de qualquer suspeita, dada sua autoridade enquanto líder religioso experiente e sua posição de sapiência (um ancião). Além disso, tem-se a presença do nome da igreja, marca de verossimilhança e referencialidade (embora o conto não deixe clara a localização, o leitor de então imediatamente poderia associá-la à famosa igreja colonial localizada no largo homônimo, no centro histórico do Rio de Janeiro). O primeiro parágrafo já antecipa que irá narrar "uma aventura extraordinária", ou seja, coloca o leitor imediatamente diante de um relato fantástico que deverá tomar como verdade, posto que proveniente de uma autoridade religiosa que estaria narrando, enquanto testemunha ocular, acontecimentos verídicos, embora extraordinários: o diálogo de vários santos materializados ou personificados a partir de suas estátuas tarde da noite, na escuridão de uma igreja iluminada por uma fonte sobrenatural. Os santos estariam em reunião, discutindo e comparando as súplicas de alguns devotos da igreja e decidindo qual deles seria o mais honesto e deveria, portanto, ser perdoado ou ter suas súplicas atendidas. Os santos, todos nomeados e realmente pertencentes ao rol de santos da igreja católica, são descritos como piedosos, em alguns casos, ou mais implacáveis e irônicos, em outros, assumindo, assim, características bastante humanizadas. Discorrem longamente sobre a alma de alguns fiéis, contraditória em relação ao teor de suas 
preces e promessas: desfilam pelo diálogo dos santos figuras como a da adúltera e do avaro, tipificados e, ao mesmo tempo, personificados por meio de seus nomes e histórias de vida.

O narrador, capelão mencionado logo no início do conto, relata em detalhes o teor das conversas, citando-as todas, de memória, o que assevera ao leitor a veracidade dos eventos narrados. Por outro lado, também suscita no leitor mais atento a dúvida sobre a aventura extraordinária. Afinal, passados tantos anos, seria esse um relato a ser, de fato, tido como verídico? O conto termina com o narrador que desperta com a luz do dia, corre a abrir janelas e portas da igreja para "entrar o sol, inimigo dos maus sonhos" (p. 444). Esse final coloca em xeque a credulidade do leitor. Afinal, teria sido essa uma real aventura extraordinária, momento de alumbramento e revelação do divino? Seria esse o destino dos homens, o de ser julgados ainda em vida pelos santos, vistos como próximos ao homem, e, ao mesmo tempo, representantes do divino, portanto, acima de qualquer suspeita? Teria isso sido apenas um mau sonho, um pesadelo sofrido como real por um pároco adormecido dentro da igreja? O leitor desse conto, assim como em "A Chinela Turca" e "O Espelho", é deixado na dúvida entre crer e desconfiar, dúvida essa cuidadosamente tecida por meio de recursos narrativos hiper-realistas, como discute Roas (no caso desse conto, dados pelos nomes da igreja e dos santos e pelo rico detalhamento do teor das conversas durante o "julgamento" dos fiéis), recursos esses que são desmembrados, como afirma Iveson (2008), pelo tropo fantástico presente nesses e em outros contos machadianos.

\title{
CONSIDERAÇÕES FINAIS
}

Nos três contos brevemente analisados aqui, a irrupção do não familiar, do elemento insólito dentro de um contexto adensado, ricamente detalhado, e, portanto, passivel de credulidade e reconhecimento por parte do leitor, pode, a nosso ver, ser visto como exemplo do tropo fantástico e de autolegitimação, conceitos aos quais Iveson se remete, e os quais Roas define como subversão do indefinido dentro de uma narrativa hiper-realista. Assim, as marcas do contexto do Rio de Janeiro do século XIX dentro dos três contos aqui analisados ajudam a criar o efeito de verossimilhança e, ao mesmo tempo, o que Freud chama de Das Unheimliche, ou seja, a inclusão do não familiar dentro do familiar, e a suscitar a dúvida ou hesitação no leitor, tal como discutida por Todorov (2008).

\section{Machado de Assis' fantastic and the context of 19Th-Century Rio de Janeiro in "Turkish Slipper", “The Looking Glass" and "Between Saints"}

\begin{abstract}
This article aims at analyzing Machado de Assis' short stories titled "Turking Slipper", "The Looking Glass: draft of a theory of the human soul" and "Between Saints" in view of the fantastic mode, searching for understanding how the author's social-historical context, 19th-century Rio de Janeiro, helps to build up verisimilitude and, at the same time, subvert it. We shall base ourselves on Iveson's (2008) and Roas' studies (2014), in relation to the concepts of the fantastic hope, the dismemberment of reality and hyper-realism.
\end{abstract}


Keywords: Machado's short story. The fantastic mode. The social-historical context.

\section{REFERÊNCIAS}

ASSIS, J. M. M. Machado de Assis. 3. ed. Rio de Janeiro: Editora Nova Aguilar, 2015. (Obra completa, v. II).

BESSIĖRE, I. Le récit fantastique. La poétique de l'incertain. Paris: Larousse Université, 1973.

CAILlOIS, R. De la féerie à la science fiction. Prólogo. In: CAILLOIS, R. Anthologie du fantastique. Paris: Gallimard, 1985 [1958]. p. 7-24.

CESERANI, R. O fantástico. Tradução Nilton Cezar Tridapalli. Curitiba: Editora UFPR/EDUEL, 2006.

DERRIDA, J. Force of law: the "mystical foundation of authority". In: CORNELL, D.; ROSENFELD, M.; CARLSON, D. G. (Ed.). Deconstruction and the possibility of justice. New York: Routledge, 1992. p. 3-67.

FREUD, S. The uncanny. In: FREUD, S. The standard edition of the complete psychological works. London: The Hogarth Press, 1955 [1919]. v. XVII, p. 217-255. FURTADO, F. A construção do fantástico na narrativa. Lisboa: Livros Horizonte, 1980. IVESON, R. A politics of disease: the fantastic trope and the dismemberment of reality. eSharp, n. 11, p. 1-28, 2008. Disponivel em: <http://www.gla.ac.uk/ research/az/esharp/issues/11/>. Acesso em: 28 mar. 2015.

JACKSON, R. Fantasy: the literature of subversion. London; New York: Methuen, 1981.

MALRIEU, J. Le fantastique. Paris: Hachette, 1992.

PAULHAN, J. The flowers of Tarbes, or terror in literature. Translation Michael Syrotinski. Urbana; Chicago: University of Illinois Press, 2006 [1941].

ROAS, D. A ameaça do fantástico. Aproximações teóricas. Tradução Julián Fuks. São Paulo: Unesp, 2014.

TODOROV, T. Introdução à literatura fantástica. Tradução Maria Clara Correa Castello. São Paulo: Perspectiva, 2008. (Coleção Debates).

VILLANUEVA, D. Teorias del realismo literário. Instituto de España. Madrid: Espasa Calpe, 1992. 